\title{
Diabetes 2030: Insights from Yesterday, Today, and Future Trends
}

\author{
William R. Rowley, MD, Clement Bezold, PhD, Yasemin Arikan, BA, \\ Erin Byrne, $\mathrm{MPH}^{2}$, and Shannon Krohe, $\mathrm{MPH}^{3}$
}

\begin{abstract}
To forecast future trends in diabetes prevalence, morbidity, and costs in the United States, the Institute for Alternative Futures has updated its diabetes forecasting model and extended its projections to 2030 for the nation, all states, and several metropolitan areas. This paper describes the methodology and data sources for these diabetes forecasts and discusses key implications. In short, diabetes will remain a major health crisis in America, in spite of medical advances and prevention efforts. The prevalence of diabetes (type 2 diabetes and type 1 diabetes) will increase by $54 \%$ to more than 54.9 million Americans between 2015 and 2030; annual deaths attributed to diabetes will climb by $38 \%$ to 385,800 ; and total annual medical and societal costs related to diabetes will increase 53\% to more than $\$ 622$ billion by 2030 . Improvements in management reducing the annual incidence of morbidities and premature deaths related to diabetes over this time period will result in diabetes patients living longer, but requiring many years of comprehensive management of multiple chronic diseases, resulting in dramatically increased costs. Aggressive population health measures, including increased availability of diabetes prevention programs, could help millions of adults prevent or delay the progression to type 2 diabetes, thereby helping turn around these dire projections.
\end{abstract}

\section{Introduction}

D IABETES AND ITS COMPLiCATIONS, deaths, and societal costs have a huge and rapidly growing impact on the United States. Between 1990 and 2010 the number of people living with diabetes tripled and the number of new cases annually (incidence) doubled. ${ }^{1}$ Adults with diabetes have a $50 \%$ higher risk of death from any cause than adults without diabetes, in addition to risk for myriad complications. ${ }^{2} \mathrm{Re}-$ ducing this burden will require efforts on many fronts-from appropriate medical care to significant public health efforts and individual behavior change across the nation, through state- and community-specific efforts. Public awareness is a key first step. For this purpose, the Centers for Disease Control and Prevention (CDC) releases national diabetes statistics every 2 years, providing a point-in-time picture of diabetes for the country as a whole. However, state and metropolitan diabetes forecasts with projections several years into the future also are useful as health professionals and decision makers contemplate actions to address the diabetes epidemic. Therefore, the Institute for Alternative Futures (IAF) has prepared 2015, 2020, 2025, and 2030 diabetes forecasts for the entire United States, every state, and several metropolitan statistical areas, all of which are easily accessible on the Internet. ${ }^{3}$

This study shows how past trends, current data, and future projections provide valuable insights about the possible course of diabetes.

\section{Methods}

Prevalence of prediabetes, undiagnosed diabetes, and diagnosed diabetes

The IAF Diabetes 2030 Model utilizes many features of the previous 2025 Model that were updated based on new

\footnotetext{
${ }^{1}$ Institute for Alternative Futures, Alexandria, Virginia.

${ }^{2}$ Public Affairs Strategy, Novo Nordisk Inc., Plainsboro, New Jersey.

${ }^{3}$ Novo Nordisk Inc., Washington, District of Columbia.
}

(C) Rowley et al, 2016; Published by Mary Ann Liebert, Inc. This Open Access article is distributed under the terms of the Creative Commons Attribution Noncommercial License (http://creativecommons.org/licenses/by-nc/4.0/) which permits any noncommercial use, distribution, and reproduction in any medium, provided the original author(s) and the source are credited. 
diabetes data trends. ${ }^{4}$ Estimates of diagnosed diabetes prevalence to 2030 are derived from Boyle et al's sophisticated dynamic modeling paper, which projected the diabetes burden to $2050 .{ }^{5}$ The present study utilized Boyle et al's conservative 3-state dynamic model, middle-ground scenario of low, steady diabetes incidence (8.4 cases per 1000 adult population) and low diabetes mortality. However, 2 recent studies suggest that the diagnosed diabetes incidence trend has begun to level off and could be declining. ${ }^{6,7}$ It is difficult to know if this trend will continue, and hard to forecast to what extent long-term prevalence might be reduced because so many other factors, such as an aging population and falling diabetes morbidity and mortality, enter into the equation. Because the incidence used in Boyle et al's model is higher than present experience, the research team reduced its prevalence growth to 2030 by a modest $2 \%$ to prevent overestimating the magnitude of diagnosed diabetes.

The team made 2 other significant changes. Their 2025 Model utilized Boyle et al's projection that undiagnosed diabetes would be $33 \%$ of total diabetes in 2015 , declining to $25 \%$ in 2030. Based on the trend of CDC national diabetes statistics $(29.8 \%$ of total diabetes being undiagnosed in $2005,24.2 \%$ in $2007,27.1 \%$ in 2010 , and $27.8 \%$ in 2012), ${ }^{2,8,9,10}$ the IAF model projects $27 \%$ will be undiagnosed in 2015 , declining to $24 \%$ in 2030 . Second, the prevalence of prediabetes has been progressively climbing in CDC national statistics (20\% of the adult population in $2000,26 \%$ in $2007,35 \%$ in 2010 , and $37 \%$ in 2012 ), so the IAF model used $38 \%$ of the population ages 20 years and older having prediabetes in 2015 , slowly increasing to $40 \%$ in 2030 .

Each state and metropolitan area has its unique prevalence rates. Based on the latest CDC data, Dall et al calculated the prevalence of diagnosed, undiagnosed, and prediabetes for every state for 2012. ${ }^{11}$ Utilizing the ratio of each state to US prevalence rates and assuming this rate remains constant between 2015 and 2030 (there are no data available to estimate a state's future variation), state diagnosed, undiagnosed, and prediabetes forecasts were created. Metropolitan area forecasts utilized their state prevalence rates.

\section{Population data}

The national census data (including race and Hispanic origin) population projections to 2030 came from 2010 US Census Bureau data. ${ }^{12}$ Unfortunately, state projections have not been updated with the 2010 census so 2000 census data were used. ${ }^{13}$ Census data of state minority projections to 2025 were last calculated from the 1990 census, and most states do not have their own projections to 2030. The research team therefore considered state minority forecasts too imprecise to include them in the IAF Diabetes 2030 Model. Metropolitan statistical area population projections to 2030 came from Demographia ${ }^{14}$ and Bizjournals. ${ }^{15}$

\section{Diabetes morbidity and mortality}

The CDC National Center for Health Statistics tracks visual impairment, ${ }^{16}$ end-stage renal failure, ${ }^{17}$ and lower extremity amputation ${ }^{18}$ annual trends related to diabetes. Analysis of the latest available 10-year data revealed a $19 \%$ decline in the prevalence of reported visual impairment in those with diagnosed diabetes, a $26 \%$ decline in the annual incidence of new end-stage renal failure, and a $65 \%$ decline in the incidence of nontraumatic lower extremity amputations. An additional 30\% decline over the 20-year period from 2010 to 2030 for each morbidity was factored in as a plausible estimate to account for anticipated increasing access and more aggressive medical management. Each minority group had different morbidity trends, which were similarly calculated and applied for total US minority projections.

To calculate the percent risk of death from diabetes, the research team used annual death data published for the most recent 10 years (2000 to 2010) from the National Vital Statistic Reports. ${ }^{19}$ A death from diabetes is defined as a death for which the underlying cause listed on the death certificate is diabetes. Plotting this trend line of annual percent incidence of death per individual with diagnosed diabetes revealed a $40 \%$ decline. The model assumes a modest additional 25\% decline over the period between 2010 and 2030 to calculate deaths caused by diagnosed diabetes. Recent CDC diabetes fact sheets also include deaths for which diabetes was a contributing cause of death on the certificate. For instance, the latest data from 2010 state 69,071 death certificates listed diabetes as the cause and 234,051 death certificates listed diabetes as a contributing cause of death (almost 3.4 times higher). ${ }^{2}$ Therefore, the projected declining percentage of those with diagnosed diabetes dying per year directly because of diabetes times this ratio provides the total number of annual deaths to which diabetes contributed. Specific death rate trends for minorities and seniors ages 65 and older also are derived from the National Vital Statistics Reports data.

\section{The cost of diabetes}

The 2014 paper by Dall et al calculated the direct medical costs and indirect economic burden of diagnosed diabetes, undiagnosed diabetes, and prediabetes for the United States and all states in 2012. ${ }^{11}$ The research team adjusted these costs on a per person basis to 2015 dollars, and used them when projecting costs out to 2030 for the United States, all states, and selected metropolitan statistical areas.

\section{Results}

Between 2015 and 2030, the IAF Diabetes Model projects that the total number of people with type 2 and type 1 diabetes will increase by $19,629,000$ to $54,913,000$ people, a $54 \%$ increase. The cost of diabetes in 2015 dollars will increase to $\$ 622.3$ billion, a $53 \%$ increase. Table 1 presents the data for the United States between 2015 and 2030 for the population as a whole and the 2 largest minority groupsHispanic Americans and African Americans. National data for Asian Americans, Native Americans, and seniors ages 65 and older are available online, along with data for all 50 states and several metropolitan statistical areas. ${ }^{3}$

Figure 1 shows 4 maps with the age-adjusted prevalence of total diabetes as a percent of the total population for every state in the United States between 2015 and 2030. It is clear that there is a wide disparity in prevalence rates among states. The increase in diabetes prevalence between 2015 and 2030 was less than $3 \%$ for Alaska, Colorado, and Utah, 
Table 1. US Diabetes Forecasts, 2015 to 2030

\begin{tabular}{|c|c|c|c|c|}
\hline & 2015 & 2020 & 2025 & 2030 \\
\hline \multicolumn{5}{|l|}{ Total United States } \\
\hline Population & $321,363,000$ & $333,896,000$ & $346,407,000$ & $358,471,000$ \\
\hline Prediabetes & $90,644,000$ & $97,284,000$ & $103,950,000$ & $107,713,000$ \\
\hline Diagnosed diabetes & $26,019,000$ & $32,021,000$ & $37,349,000$ & $41,733,000$ \\
\hline Undiagnosed diabetes & $9,625,000$ & $11,250,000$ & $12,450,000$ & $13,180,000$ \\
\hline Total with diabetes & $35,644,000$ & $43,271,000$ & $49,799,000$ & $54,913,000$ \\
\hline \multicolumn{5}{|l|}{ Complications: } \\
\hline Visual impairment & $4,267,000$ & $5,098,000$ & $5,770,000$ & $6,260,000$ \\
\hline Renal failure & 62,020 & 73,650 & 82,900 & 89,390 \\
\hline Leg amputation & 53,860 & 60,840 & 65,360 & 67,190 \\
\hline Annual deaths attributable to DM & 280,210 & 329,260 & 364,650 & 385,840 \\
\hline Total annual cost (2015 dollars) & $\$ 407.6 \mathrm{~B}$ & $\$ 490.2 \mathrm{~B}$ & $\$ 564.2 \mathrm{~B}$ & $\$ 622.3 \mathrm{~B}$ \\
\hline Annual medical costs & $\$ 312.2 \mathrm{~B}$ & $\$ 374.2 \mathrm{~B}$ & $\$ 428.9 \mathrm{~B}$ & $\$ 472.0 \mathrm{~B}$ \\
\hline Annual nonmedical costs & $\$ 95.4 \mathrm{~B}$ & $\$ 116.7 \mathrm{~B}$ & $\$ 135.3 \mathrm{~B}$ & $\$ 150.3 \mathrm{~B}$ \\
\hline \multicolumn{5}{|l|}{ Hispanic Americans } \\
\hline Population & $56,950,000$ & $63,800,000$ & $71,007,000$ & $78,700,000$ \\
\hline Prediabetes & $16,063,000$ & $18,589,000$ & $21,308,000$ & $23,648,000$ \\
\hline Diagnosed diabetes & $5,063,000$ & $6,845,000$ & $8,609,000$ & $10,262,000$ \\
\hline Undiagnosed diabetes & $1,706,000$ & $2,150,000$ & $2,552,000$ & $2,894,000$ \\
\hline Total with diabetes & $6,769,000$ & $8,995,000$ & $11,161,000$ & $13,156,000$ \\
\hline \multicolumn{5}{|l|}{ Complications: } \\
\hline Visual impairment & 759,400 & 987,100 & $1,207,100$ & $1,389,900$ \\
\hline Renal failure & 14,680 & 19,990 & 23,760 & 26,890 \\
\hline Leg amputation & 16,400 & 21,220 & 24,360 & 25,910 \\
\hline Annual deaths attributable to DM & 62,000 & 77,350 & 89,670 & 98,270 \\
\hline Total annual cost (2015 dollars) & $\$ 77.7 \mathrm{~B}$ & $\$ 102.6 \mathrm{~B}$ & $\$ 127.1 \mathrm{~B}$ & $\$ 149.9 B$ \\
\hline Annual medical costs & $\$ 59.3 \mathrm{~B}$ & $\$ 77.9 \mathrm{~B}$ & $\$ 96.3 \mathrm{~B}$ & $\$ 113.4 \mathrm{~B}$ \\
\hline Annual nonmedical costs & $\$ 18.4 \mathrm{~B}$ & $\$ 24.7 \mathrm{~B}$ & $\$ 30.8 \mathrm{~B}$ & $\$ 36.5 B$ \\
\hline \multicolumn{5}{|l|}{ African Americans } \\
\hline Population & $41,010,000$ & $43,000,000$ & $43,800,000$ & $45,000,000$ \\
\hline Prediabetes & $11,567,000$ & $12,528,000$ & $13,144,000$ & $13,522,000$ \\
\hline Diagnosed diabetes & $4,334,000$ & $5,374,000$ & $6,158,000$ & $6,795,000$ \\
\hline Undiagnosed diabetes & $1,228,000$ & $1,449,000$ & $1,574,000$ & $1,655,000$ \\
\hline Total with diabetes & $5,562,000$ & $6,823,000$ & $7,732,000$ & $8,450,000$ \\
\hline \multicolumn{5}{|l|}{ Complications: } \\
\hline Visual impairment & 775,700 & 952,400 & $1,072,600$ & $1,154,500$ \\
\hline Renal failure & 16,640 & 19,830 & 22,230 & 23,850 \\
\hline Leg amputation & 14,040 & 16,660 & 17,430 & 17,190 \\
\hline Annual deaths attributable to DM & 73,880 & 84,530 & 89,320 & 90,640 \\
\hline Total annual cost (2015 dollars) & $\$ 64.2 \mathrm{~B}$ & $\$ 78.3 \mathrm{~B}$ & $\$ 88.6 \mathrm{~B}$ & $\$ 96.9 \mathrm{~B}$ \\
\hline Annual medical costs & $\$ 48.8 B$ & $\$ 59.2 \mathrm{~B}$ & $\$ 66.9 \mathrm{~B}$ & $\$ 73.0 \mathrm{~B}$ \\
\hline Annual nonmedical costs & $\$ 15.4 \mathrm{~B}$ & $\$ 19.1 \mathrm{~B}$ & $\$ 21.7 \mathrm{~B}$ & $\$ 23.9 \mathrm{~B}$ \\
\hline
\end{tabular}

DM, diabetes mellitus.

whereas it was more than $5 \%$ in Alabama, Florida, Mississippi, and West Virginia. In 2030 this model predicts that diabetes will impact $10.2 \%$ of the total population of Utah, more than $18 \%$ in Alabama, Florida, and Mississippi, and $20.5 \%$ in West Virginia.

Comparing the results from the new Diabetes 2030 Model to IAF's prior Diabetes 2025 Model reveals that there will be $1,966,700$, or $4.5 \%$, fewer people with diagnosed diabetes in 2030. Ninety-five percent of the decline is caused by the Census Bureau reducing its 2030 population projection by 15 million in the 2010 census report compared to its 2000 forecast. $^{12,20}$ The remainder of the decline is related to an adjustment for the recent leveling of the incidence trend. Additionally, in the new model there will be $1,519,800$, or $10.3 \%$, fewer people with undiagnosed diabetes because of lower undiagnosed diabetes prevalence rates. Therefore, total diabetes is projected to be $3,426,500$, or $5.8 \%$, lower using the Diabetes 2030 Model. However, prevalence of prediabetes is higher in this model, resulting in 12,581,900 more individuals with prediabetes (a 13.2\% increase) in 2030.

\section{Discussion}

The process of exploring past and present data trends to ponder their implications for the future leads to several insights about the future course of diabetes if America remains on its present course.

The incidence of diabetes may be leveling off. Geiss showed that although diabetes incidence more than doubled from 3.2 cases per 1000 adults in 1990 to 8.8 cases per 1000 in 2008, the incidence held steady statistically in 2012 at 7.1 cases per $1000 .^{6}$ In addition, a 2014 study looking at Framingham Heart Study data found the incidence of diabetes 


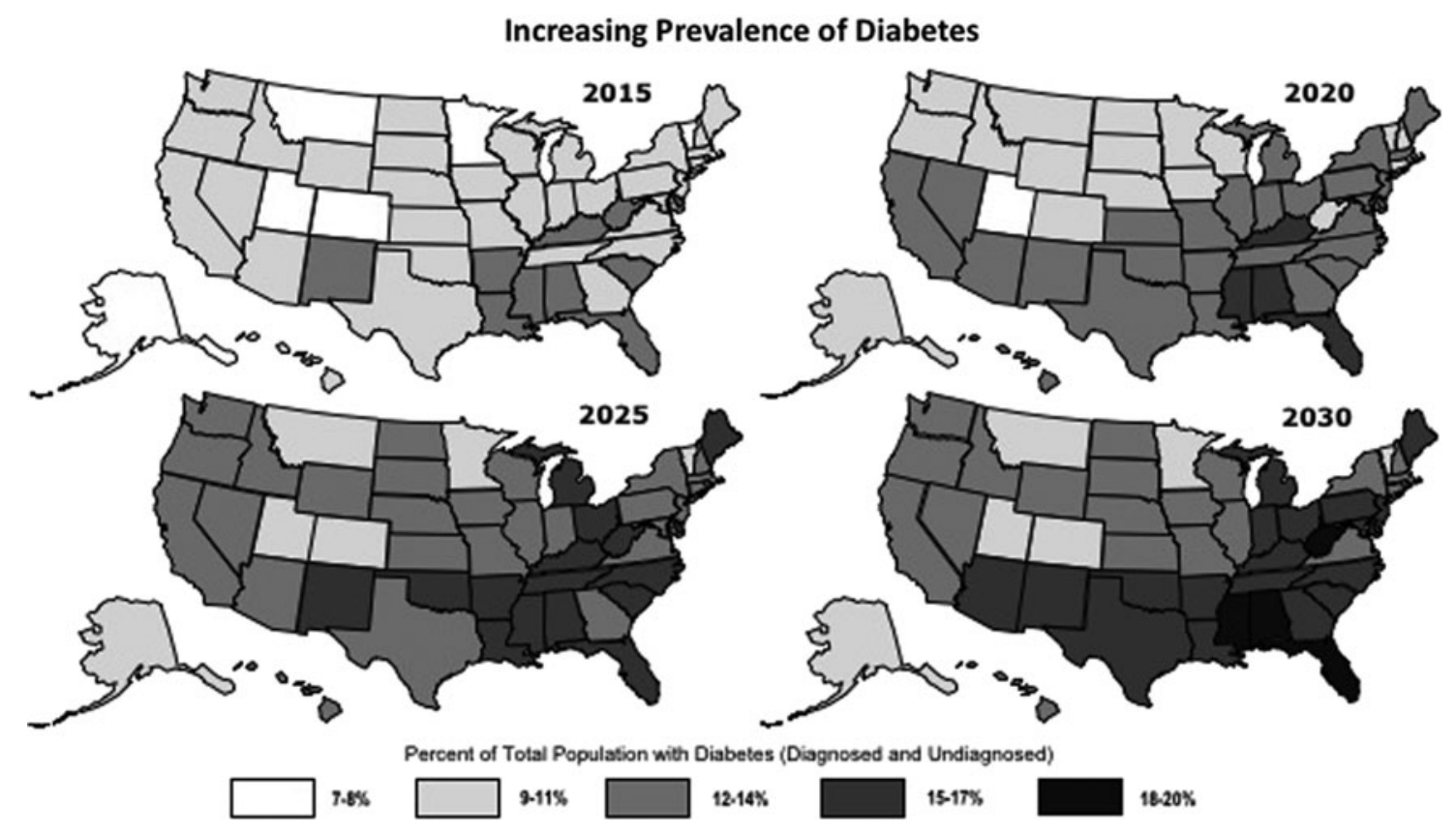

FIG. 1. Prevalence of total diabetes as a percent of total population for each state for 2015, 2020, 2025, and 2030 based on the Diabetes 2030 Model (age adjusted to standard population).

remained steady in the 2000 s in spite of rising obesity. ${ }^{7}$ However, the just released National Health and Nutrition Examination Survey found almost $38 \%$ of American adults were obese in 2013-2014 up from almost 35\% in 2011-2012, suggesting that obesity has not yet leveled off. ${ }^{21}$ Increasing obesity may lead to increasing diabetes. ${ }^{22}$ Therefore, it is too early to know whether the promising diabetes incidence trend toward equilibrium will continue. The IAF Diabetes 2030 Model has a steady incidence rate to prevent overestimating prevalence growth.

The annual incidence of new complications related to diabetes is declining. The present study found a $26 \%$ decline in annual incidence of new end-stage renal disease related to diabetes between 1998 and 2008, a 65\% decline in incidence of nontraumatic lower extremity amputation in the population with diabetes between 1999 and 2009, and a 19\% decline in prevalence of reported visual impairment in those with diagnosed diabetes between 2000 and 2010. Supplementing the data from the present study, Gregg et al showed a $68 \%$ decline in the incidence of myocardial infarctions and a $53 \%$ decline in strokes in those with diabetes, in addition to a $64 \%$ decline in deaths related to hyperglycemic crisis between 1990 and 2010. ${ }^{1}$

The annual incidence of deaths related to diabetes is declining. The present study found a $40 \%$ decline in the incidence of deaths directly caused by diabetes on the death certificate between 2000 and 2010, and the model projects a further $25 \%$ decline between 2010 and 2030. Gregg et al found that among adults with diabetes, the cardiovascular death rate declined by $40 \%$ between 1990 and 2006 and that all-cause mortality declined by $23 \% .^{23}$ The declines among those with diabetes exceeded the declines among those without diabetes, resulting in a more than $50 \%$ reduction of the excess death rates attributed to diabetes. Another 2014 article by Gregg et al calculated that the number of life years lost to diabetes diagnosed at age 40 declined from 7.7 years in 1990-1999 to 5.8 years in 2000-2011 for men and from 8.7 to 6.8 years for women. ${ }^{24}$

Management of diabetes patients is progressively improving. Multiple studies have shown that complications can be reduced significantly with intensive control of glucose, blood pressure (BP), and lipid levels in type 2 diabetes. $^{25,26,27,28}$ Medical care for people with diabetes is improving. Between 1999 and 2010, the US health care system achieved modest improvement in 5 out of 6 recommended goals for diabetes care: glycosylated hemoglobin (A1c) $<7.0 \%$ (7.9\% improvement), BP $<130 / 80 \mathrm{mmHg}(11.7 \%$ improvement), low-density lipoprotein (LDL) cholesterol $<100 \mathrm{mg} / \mathrm{dl}$ (20.8\% improvement), and an annual foot exam (6.8\% improvement). Unfortunately, no improvement was seen in annual eye exams, and nearly half of all patients failed to meet at least 1 recommended goal for diabetes care. Additionally only $14.3 \%$ met the target for all 3 tested measures (A1c, BP, and LDL cholesterol) plus were not smoking. ${ }^{29}$ Several studies have shown poor adherence to medication regimens among patients with type 1 and type 2 diabetes. ${ }^{30}$ A 2014 study by Li et al found that during 20112012 only $6.8 \%$ of privately insured, newly diagnosed adults participated in Diabetes Self-Management Education and Training within the first year after diagnosis, even though it is covered by a majority of insurance plans and is strongly recommended. ${ }^{31}$ Because participation requires a physician referral, this highlights a huge gap between a recommended guideline and current practice.

Prevalence of total diabetes, associated major complications, and deaths are all increasing. In spite of the apparent stabilizing incidence of diabetes, the prevalence of total diabetes is projected to grow 54\% from 35,644,000 to 54,913,000 between 2015 and 2030. Also during this time period, the annual number of people with diabetes with new 
end-stage renal disease will increase by 27,370 , and the number of new amputations will increase by 13,330. The annual number of deaths to which diabetes contributed will rise by 106,630 . A growing population is a factor, but all these numbers are growing faster than the population. Several other factors seem to be responsible ${ }^{6}$ : (1) An aging population that, overall, is living longer will result in more people with diabetes as incidence increases dramatically in later life. (2) The significant decline in the incidence of deaths caused by diabetes means those with diabetes will be living longer, many with significant chronic comorbidities. (3) The increasing population of African Americans and Hispanic Americans, who are at higher risk of diabetes, also adds to increased prevalence of the disease. (4) Finally, the dramatic increase in type 2 diabetes in children and adolescents, rising from $3 \%$ of new cases of diabetes in children pre-1990s to $45 \%$ of new cases in 2005 , means more young and middle-aged adults will be living with diabetes. ${ }^{32}$

The cost of diabetes is increasing dramatically. Between 2015 and 2030 the total costs in the United States are expected to increase from $\$ 408$ billion to $\$ 622$ billion, a $53 \%$ increase (Table 1). The cost of diagnosed diabetes increased by $41 \%$ between 2007 and 2012, but individual costs of diabetes care increased only $19 \%$ whereas national health care expenditures increased $24 \%$. Therefore, increased prevalence, not increased cost per patient, is causing the increased economic burden of diabetes. ${ }^{33}$ Also, between 2007 and 2012 the cost of prediabetes increased $74 \%$ to $\$ 44$ billion, so the increasing prevalence of diabetes and prediabetes is the driving force behind the dramatically increasing economic burden of diabetes. ${ }^{11}$

Between 1987 and 2011 prescription medications accounted for $55 \%$ of the per capita increase in medical spending for diabetes. ${ }^{34}$ Prescription drug prices rose $10.9 \%$ in 2014 and again more than $10 \%$ in $2015 .{ }^{35}$ In 2014, for the fourth year in a row, per person spending on diabetes drugs was higher than any other class of traditional drug, and fewer than half of diabetes prescriptions were for generic drugs. ${ }^{36}$ Because new advanced diabetes drugs tend to be much more expensive than those replaced, it is quite possible that the medical costs of diabetes in 2030 will be significantly higher than the present study's projections.

\section{Major initiatives are needed to turn around the growing diabetes epidemic}

Diagnosed diabetes. The knowledge and treatment modalities for successfully managing diabetes are well established, but success requires a collaborative team working diligently with the patient and family to achieve optimal health. There is much room for improvement in health care delivery to obtain continuous access to care, consistently attend to all risk factors and comorbidities, and to help patients succeed in compliance with medications and healthy living.

Undiagnosed diabetes. One in 4 Americans with diabetes do not know that they have it, but it can lead to lifethreatening complications. ${ }^{2}$ Current screening criteria fail to detect more than $50 \%$ of undiagnosed diabetes. ${ }^{33}$ The recent final diabetes screening guideline from the US Preventive Services Task Force, published October 27, 2015, expands the population of adults recommended for screening from only those with hypertension (2008 guideline) to all adults ages 40 to 70 years who are overweight or obese. ${ }^{37}$ Wide dissemination and implementation of these screening criteria, even though they are more restrictive than American Diabetes Association guidelines, should help identify a much greater percentage of those adults with undiagnosed diabetes and prediabetes.

Prediabetes. The research team forecasts that the number of Americans with prediabetes will climb from 90.6 million in 2015 to 107.7 million in 2030. This increased prevalence means $30 \%$ of all Americans and $51 \%$ of all seniors would have prediabetes. Currently only about $10 \%$ of those adults with prediabetes are aware of their condition, and without effective intervention, up to a third of them will go on to develop diabetes within 5 years. ${ }^{38}$ Programs such as the Diabetes Prevention Program clinical trial have shown that intensive lifestyle interventions can reduce the risk of going on to develop type 2 diabetes by $58 \%$ in overweight or obese adults with prediabetes. ${ }^{35}$

The best solution for turning around the diabetes epidemic is preventing prediabetes and its progression to diabetes in the first place. Achieving such an outcome calls for addressing underlying societal risk factors that can contribute to unhealthy lifestyles, and would require a "population-wide" approach that addresses health promotion, obesity prevention, and creates a physical, cultural, and psychological environment that supports healthy living naturally. This outcome could not be achieved by individual health providers and patients alone, but requires integrated systems of care incentivized for desired health outcomes. It also would require a political will for effective policies and commitment of the public at all levels. These strategies are mutually reinforcing and may have a greater impact if addressed at the state and local levels.

\section{Limitations}

There were several limitations in this analysis. Forecasting 15 years into the future carries the caveat: if current trends do not change. Technological advances follow a general pattern, but sometimes there can be profound and unexpected shifts. People tend to be largely resistant to change, especially health behavior change. Unexpected cultural shifts and other factors prompting change are possible. The research team has been consistent in using CDC statistics, the basic Boyle et al (CDC) 2050 projection model and the Dall et al cost model. In some cases, ideal data are not available, especially regarding minorities. In addition, excellent research from different studies at times reaches quite different conclusions. The research team has been explicit about the assumptions they have made, and have been conservative in their forecasts of future trends.

\section{Conclusions}

To support efforts at public awareness, and the work of health professionals and policy makers at many levels, the research team has updated projections out to 2030 for the United States, all 50 states, and many metropolitan areas, and made them freely available online. The team finds that in spite of medical advances and prevention efforts, diabetes 
presents a major health crisis in terms of prevalence, morbidity, and costs, and that this crisis will worsen significantly over the next 15 years. It is important to enhance screening, education, and support efforts at the local, state, and federal levels to appropriately screen for diabetes and prediabetes. Also, in addition to effective management for all those with diabetes, success will require aggressive efforts to identify adults with prediabetes and to intervene to help them prevent or delay the progression to type 2 diabetes in the first place. Another daunting challenge in preventing diabetes and prediabetes is changing cultural norms and societal behavior and structures in order to support healthy living. Aggressive efforts are urgently needed if we want to significantly reduce the diabetes epidemic by 2030 .

\section{Acknowledgments}

The authors thank Alisa B. Schiffman, DO of Novo Nordisk, for reviewing the proposed methodology for developing the 2030 diabetes forecasts. The authors thank Jerry Franz, BA, Karin Gillespie, MBA, Megan Olsen, $\mathrm{MPH}$, Edward Kimball, PhD, and Cory Gamble, DO of Novo Nordisk, for reviewing draft manuscripts.

\section{Author Disclosure Statement}

Drs. Rowley and Bezold, and Ms. Arikan, Ms. Byrne, and Ms. Krohe declared the following conflicts of interest with respect to the research, authorship, and/or publication of this article: Dr. Rowley, Dr. Bezold, and Ms. Arikan are employed by the Institute for Alternative Futures (IAF), an independent nonprofit futures institute. IAF has received grants in the past from many health care organizations and pharmaceutical industry clients for health futures work. None of the 3 authors receive any other compensation from Novo Nordisk; they have no conflict of interest issues to report. Ms. Byrne and Ms. Krohe are employees of Novo Nordisk Inc. They reviewed all drafts of the methodology, the generated diabetes data, and the manuscripts that were developed and written by Dr. Rowley, Dr. Bezold, and Ms. Arikan. They provided their suggestions.

The authors received the following financial support for this article: Funding for this study was provided by Novo Nordisk Inc.

\section{References}

1. Gregg EW, Li Y, Wang J, et al. Changes in diabetes-related complications in the United States, 1990-2010. N Engl J Med 2014;370:1514-1523.

2. Centers for Disease Control and Prevention. National diabetes statistics report: Estimates of diabetes and its burden in the United States, 2014. Available at: <http://www.cdc. gov/diabetes/pubs/statsreport14/national-diabetes-reportweb.pdf $>$. Accessed February 6, 2015.

3. Institute for Alternative Futures. IAF Diabetes 2030 Model statistics for the United States, all states and several metropolitan areas. Available at: <http://www.altfutures.org/ diabetes2030>.

4. Rowley WR, Bezold C. Creating public awareness: State 2025 diabetes forecasts. Pop Health Manag 2012;15:194-200.

5. Boyle JP, Thompson TJ, Gregg EW, Barker LE, Williamson DF. Projection of the year 2050 burden of diabetes in the US adult population: Dynamic modeling of incidence, mortality and prediabetes prevalence. Popul Health Metr 2010;8:29.

6. Geiss LS, Wang J, Cheng YJ, et al. Prevalence and incidence trends for diagnosed diabetes among adults aged 20 to 79 years, United States, 1980-2012. JAMA 2014;312: 1218-1226.

7. Abraham TM, Pencina KM, Pencina MJ, Fox CS. Trends in diabetes incidence: The Framingham heart study. Diabetes Care 2015;38(3):482-487.

8. Centers for Disease Control and Prevention. National diabetes fact sheet: United States, 2005. Available at: <http:// www.ndep.nih.gov/media/2005_National_Diabetes_Fact_ Sheet.pdf?redirect=true $>$. Accessed February 6, 2015.

9. Centers for Disease Control and Prevention. National diabetes fact sheet, 2007. Available at: <http://stacks.cdc.gov/ view/cdc/5613/>. Accessed February 6, 2015.

10. Centers for Disease Control and Prevention. National diabetes fact sheet, 2011. Available at: <http://www.cdc.gov/ diabetes/pubs/pdf/ndfs_2011.pdf $>$. Accessed February 6, 2015.

11. Dall TM, Yang W, Halder P, et al. The economic burden of elevated blood glucose levels in 2012: Diagnosed and undiagnosed diabetes, gestational diabetes mellitus, and prediabetes. Diabetes Care 2014;37:3172-3179.

12. United States Census Bureau. 2012 national population projections. 2015-2060 summary tables 2 and 4. Available at: <http://www.census.gov/population/projections/data/ national/2012/summarytables.html>. Accessed February 4, 2015.

13. United States Census Bureau. 2005 interim state population projections, 2000-2030, tables A1 and B1. Available at: $<$ http://www.census.gov/population/projections/data/state/ projectionsagesex.html>. Accessed February 4, 2015.

14. Demographia. United States metropolitan areas: 2030 population projections. Available at: <http://www.demographia .com/db-msaproj2030.pdf>. Accessed February 4, 2015.

15. Bizjournals. Projected population of 250 U.S. metros. Available at: <http://www.bizjournals.com/specials/pages/ 257.html>. Accessed July 30, 2010, for original study (no longer available online).

16. Centers for Disease Control and Prevention, Diabetes Public Health Resource. Crude and age-adjusted percentage of adults aged 18 years or older with diagnosed diabetes reporting visual impairment, United States, 1997-2011. Available at: <http://www.cdc.gov/diabetes/statistics/visual/ index.htm>. Accessed February 4, 2015.

17. Centers for Disease Control and Prevention, Diabetes Public Health Resource. Crude and age-adjusted incidence of end-stage renal disease related to diabetes mellitus (ESRD-DM) per 100,000 diabetic population, United / States, 1980-2008. Available at: <http://www.cdc.gov/ diabetes/statistics/esrd/index.htm >. Accessed February 4, 2015.

18. Centers for Disease Control and Prevention, Diabetes Public Health Resource. Crude and age-adjusted hospital discharge rates for nontraumatic lower extremity amputation per 1,000 diabetic population, United States, 19882009. Available at: <http://www.cdc.gov/diabetes/statistics/ lea/index.htm>. Accessed February 4, 2015.

19. National Vital Statistics Reports; Death: Final data for $2000=$ NVSR Vol. 50 No. 16; $2001=$ NVSR Vol. 52 No. 9; $2002=$ NVSR Vol. 53 No. 5; $2003=$ NVSR Vol. 54 No. 13; $2004=$ NVSR Vol. 55 No. 19; $2005=$ NVSR Vol. 56. No. 
10; $2006=$ NVSR Vol. 57 No. 14; $2007=$ NVSR Vol. 58 No. 19; $2008=$ NVSR Vol. 59 No. 10; 2009=NVSR Vol. 60 No. 3; $2010=$ Vol. 61 No. 4. Available at: <http://www .cdc.gov/nchs/products/nhsr.htm>. Accessed February 5, 2015.

20. United States Census Bureau. 2008 national population projections. Summary table 2: Projections of the population by selected age groups and sex for the United States: 2010 to 2050. Available at: <http://www.census.gov/population/ projections/data/national/2008/summarytables.html >. Accessed March 15, 2015.

21. Ogden CL, Carroll MD, Fryar CD, Flegel KM. Prevalence of obesity among adults and youth: United States, 20112014. NCHS data brief, No. 219, 2015. Available at: $<$ http://cdc.gov/nchs/data/databriefs/db219.htm>. Accessed November 15, 2015.

22. Menke A, Rust KF, Fradkin J, Cheng YJ, Cowie CC. Associations between trends in race/ethnicity, aging, and body mass index with diabetes prevalence in the United States: A series of cross-sectional studies. Ann Intern Med 2014;161: 328-335.

23. Gregg EW, Cheng YJ, Saydah S, et al. Trends in death rates among U.S. adults with and without diabetes between 1997 and 2006: Findings from the National Health Interview Survey. Diabetes Care 2012;35:1252-1257.

24. Gregg EW, Zhuo X, Cheng YJ, Albright AL, Narayan KMV, Thompson TJ. Trends in lifetime risk and years of life lost due to diabetes in the USA 1985-2011: A modelling study. Lancet Diabetes Endocrinol 2014;2:867-874.

25. The Diabetes Control and Complications Trial Research Group. Effect of intensive diabetes management on macrovascular events and risk factors in the diabetes control and complications trial. Am J Cardiol 1995;75:894-903.

26. UK Prospective Diabetes Study Group. Tight blood pressure control and risk of macrovascular and microvascular complications in type 2 diabetes: UKPDS 38. BMJ 1998;317: 703-713.

27. UK Prospective Diabetes Study Group. Intensive bloodglucose control with sulphonylureas or insulin compared with conventional treatment and risk of complications in patients with type 2 diabetes (UKPDS 33). Lancet 1998; 352:837-853.

28. Gaede P, Vedel P, Larsen N, Jensen GVH, Parving HH, Pedersen O. Multifactorial intervention and cardiovascular disease in patients with type 2 diabetes. $\mathrm{N}$ Engl J Med 2003;348:383-393.

29. Ali MK, Bullard KM, Saaddine JB, Cowie CC, Imperatore G, Gregg EW. Achievement of goals in U.S. diabetes care, 1999-2010. N Engl J Med 2013;368:1613-1624.
30. Cramer JA. A systematic review of adherence with medications for diabetes. Diabetes Care 2004;27:12181224.

31. Li R, Shrestha SS, Lipman R, Burrows NR, Kolb LE, Rutledge $\mathrm{S}$. Diabetes self-management education and training among privately insured persons with newly diagnosed diabetes-United States, 2011-2012. MMWR 2014; 63(46):1045-1049.

32. Pinhas-Hamiel O, Zeitler P. The global spread of type 2 diabetes mellitus in children and adolescents. J Pediatr 2005;146:693-700.

33. Cefalu WT, Petersen MP, Ratner RE. The alarming and rising costs of diabetes and prediabetes: A call for action! Diabetes Care 2014;37:3137-3138.

34. Zhuo X, Zhang P, Kahn HS, Bardenheier BH, Li R, Gregg EW. Change in medical spending attributable to diabetes: National data from 1987 to 2011. Diabetes Care 2015;38: 581-587.

35. Dennis B. Prescription drug prices jumped more than 10 percent in 2015, analysis finds. Washington Post January 11, 2016. Available at: <https://www.washingtonpost.com/ news/to-your-health/wp/2016/01/11/prescription-drug-pricesjumped-more-than-10-percent-in-2015/>. Accessed February 12, 2016.

36. Andrews M. High cost of diabetes drugs often goes overlooked. NPR August 18, 2015. Available at: <http://www .npr.org/sections/health-shots/2015/08/18/432621873/highcost-of-diabetes-drugs-often-goes-overlooked $>$. Accessed February 12, 2016.

37. Siu AL, on behalf of the U.S. Preventive Services Task Force. Screening for abnormal blood glucose and type 2 diabetes mellitus: U.S. Preventive Services Task Force recommendation statement. Ann Intern Med 2015;163: $861-868$

38. Centers for Disease Control and Prevention. National Diabetes Prevention Program. Available at: $<$ http://www .cdc.gov/diabetes/prevention/index.htm>. Accessed March $16,2015$.
Address correspondence to:
Dr. William Robert Rowley
nstitute for Alternative Futures
138 Opera Court
Centreville, Maryland 21617

E-mail: Wrowley@mac.com 